\title{
USP8 Mutations and Cell Cycle Regulation in Corticotroph Adenomas
}

\author{
Authors \\ Clarissa Silva Martins ${ }^{1}$, Renata Costa Camargo ${ }^{1}$, Fernanda Borchers Coeli-Lacchini ${ }^{1}$, Fabiano Pinto Saggioro ${ }^{2}$, \\ Ayrton Custodio Moreira', Margaret de Castro ${ }^{1}$
}

\begin{abstract}
Affiliations
1 Department of Internal Medicine, Ribeirao Preto Medical School, University of Sao Paulo, Ribeirao Preto, SP, Brazil

2 Department of Pathology, Ribeirao Preto Medical School, University of Sao Paulo, Ribeirao Preto, SP, Brazil
\end{abstract}

\author{
Key words \\ pituitary ACTH hypersecretion, pituitary neoplasms, cell \\ cycle, USP8 protein, cyclin-dependent kinase inhibitor p27 \\ received 08.07.2019 \\ accepted 18.12.2019 \\ Bibliography \\ DOI https://doi.org/10.1055/a-1089-7806 \\ Horm Metab Res 2020; 52: 117-123 \\ (c) Georg Thieme Verlag KG Stuttgart · New York \\ ISSN 0018-5043 \\ Correspondence \\ Margaret de Castro \\ Department of Internal Medicine \\ Ribeirao Preto Medical School \\ University of Sao Paulo \\ Av Bandeirantes, 3900 \\ 14049-900 Ribeirao Preto \\ SP \\ Brazil \\ Tel.: + 55163602 2940, Fax: + 551636336695 \\ castrom@fmrp.usp.br
}

\section{ABSTRACT}

Corticotroph adenomas frequently harbor somatic USP8 mutations. These adenomas also commonly exhibit underexpression of P27, a cell cycle regulator. The present study aimed to determine the influence of USP8 mutations on clinical features of Cushing's disease and to elucidate the relationship between USP8 mutations and P27 underexpression in these tumors. Retrospective study with 32 patients with Cushing's disease was followed at the Ribeirao Preto Medical School University Hospital. We evaluated the patients' clinical data, the USP8 mutation status and the gene expression of cell cycle regulators P27/CDKN1B, CCNE1, CCND1, CDK2, CDK4, and CDK6 in tumor tissue in addition to the protein expression of P27/CDKN1B. We observed somatic mutations in the exon 14 of USP8 in $31.3 \%$ of the patients. Larger tumor size was observed in patients harboring USP8 mutations $(p=0.04)$, with similar rates of remission, age of presentation, salivary cortisol at 23:00 h and after $1 \mathrm{mg}$ dexamethasone, ACTH levels, and early postoperative plasma cortisol. We observed no differences regarding the gene or protein expression of the cell cycle regulators according to USP8 mutation status. In this Brazilian series, the observed frequency of USP8 somatic mutations was similar to that reported in European ancestry populations. Although it was reasonable that USP8 mutations could contribute to cell cycle dysregulation and P27 underexpression in corticotroph adenomas, our data did not confirm this hypothesis. It is possible that increased deubiquitinase activity observed in mutated USP8 might influence other pathways related to cell growth and proliferation.

\section{Introduction}

The cell-cycle progression is synchronized by cyclins and cyclin-dependent kinases (CDKs) [1]. The misexpression of these cell cycle regulators has been associated with pituitary tumorigenesis, in animal models [2, 3] and in human pituitary adenomas [1, 4]. Notably, the underexpression of P27 or CDKN1B [cyclin-dependent kinase (CDK) inhibitor 1B] has been observed in all types of sporadic pituitary adenomas, mainly in corticotroph adenomas [5-8].

Amongst the studied mechanisms regulating P27 protein expression in sporadic pituitary corticotroph adenomas, CDKN1B mutations [9-11], promoter hypermethylation [12], or impaired translation by the misexpression of regulatory microRNAs [13] have not been frequently observed. On the other hand, P27-increased ubiquitination, phosphorylation, and subsequent degradation may account for reducing P27 expression [14-17]. Another potential mechanism that could partially explain the P27 underexpression in corticotroph adenomas is the loss of CABLES1 expression [18], also a cell cycle regulator. However, somatic CABLES1 mutations were infrequent events in a large cohort of Cushing's disease patients [19].

Although extensive evaluation of candidate genes largely failed to identify somatic mutations underlying corticotroph tumorigenesis, recent studies using next-generation sequencing shed light on this issue with the discovery of somatic mutations in the exon 
14 of USP8 (ubiquitin-specific protease 8 ) in 35-60\% of corticotroph adenomas $[20,21]$, while BRAF and USP48 mutations were observed in corticotroph adenomas carrying wild-type USP8 [22]. The USP8 gene encodes for a deubiquitinase that inhibits the lysosomal degradation of epidermal growth factor receptor (EGFR) [23]. The mutant USP8 loses the ability to bind to 14-3-3 proteins, which increases USP8 proteolytic cleavage. The cleaved fragment exhibits higher deubiquitinase activity [20], resulting in increase of EGFR, which overexpression had been previously described in these adenomas [24, 25].

P27 is a target of EGFR signaling in different cell models [26]. In human cell lines derived from estrogen receptor-alpha-negative invasive breast carcinoma, EGF treatment and EGFR phosphorylation cause nuclear translocation of JAB1 and a consequent decrease in P27 expression [27]. It has also been demonstrated that the E5 oncoprotein from the human papillomavirus type 16 promotes downregulation of P27 through EGFR signaling [28]. In corticotroph adenomas, low P27 protein expression inversely correlates with EGFR levels [24]. Considering that USP8 mutation activates EGFR-MAPK signaling, we speculate that USP8 mutations could induce P27 underexpression in corticotroph adenomas.

In order to further clarify the relationship between USP8 mutation and cell cycle dysregulation in corticotroph adenomas, we evaluated the clinical data of a series of patients with Cushing's disease, assessed their USP8 mutation status, determined the impact of USP8 mutations on the clinical features of Cushing's disease, verified the protein expression of P27 and the gene expression of $C D$ $K N 1 B, C C N E 1, C C N D 1, C D K 2, C D K 4$, and CDK6, crucial regulators of cell cycle.

\section{Subjects and Methods}

\section{Subjects}

We performed a retrospective study with 32 patients (31 females/1 male) who underwent transsphenoidal surgery for Cushing's disease (CD). All patients were followed in the Endocrine Center in the Division of Endocrinology, University Hospital of the Ribeirao Preto Medical School, University of Sao Paulo, one of the referral services for Cushing's syndrome in Brazil. This study was approved by the Institutional Ethical Committee (Process no 11071/2013) and written informed consent was obtained from all subjects. All procedures performed in studies involving human participants were in accordance with the ethical standards of the institutional and national research committee and with the 1964 Helsinki declaration and its later amendments or comparable ethical standards.

Cushing's syndrome diagnosis was established on clinical assessment and biochemical evidence of hypercortisolism, according to international criteria [29]. Briefly, biochemical confirmation was based on increased levels of urinary free cortisol and/or latenight salivary cortisol (LNSC), and non-suppression of plasma or salivary cortisol after low-dose (1 mg overnight) dexamethasone suppression test (LDDST). Plasma and salivary cortisol were measured by radioimmunoassay (RIA), as previously described [30] and to exclude the biochemical diagnosis of endogenous hypercortisolism, we used as cut off values for LNSC values lower than $350 \mathrm{ng} /$ $\mathrm{dl}$ (or $9.8 \mathrm{nmol} / \mathrm{I}$ ) and salivary cortisol levels after LDDST lower than
$150 \mathrm{ng} / \mathrm{dl}$ (or $4.2 \mathrm{nmol} / \mathrm{l}$ ) [31]. After the confirmation of hypercortisolism, ACTH dependency was determined by normal or increased basal plasma ACTH (ACTH above $2.2 \mathrm{pmol} / \mathrm{l}$ or $10 \mathrm{pg} / \mathrm{ml}$ ).

The differential diagnosis between pituitary and ectopic etiologies was performed by dynamic tests [32]. For CD, a suppression of plasma cortisol above $50 \%$ after high-dose ( 8 mg overnight) dexamethasone suppression test (HDDST) was considered and, depending on availability, CRH-test (cut-off value: increase above baseline of $35 \%$ in ACTH and of $20 \%$ in cortisol) or DDAVP test (cutoff value: increase above baseline of $50 \%$ in ACTH and of $20 \%$ in cortisol) was performed. In the case of concordant dynamic biochemical studies, patient underwent pituitary imaging. If the patient presented a focal lesion (larger than $5 \mathrm{~mm}$ in diameter) on pituitary MRI, CD was diagnosed and no further evaluation was performed. In the case of discordant or equivocal biochemical or radiological studies, bilateral inferior petrosal sinus sampling (BIPSS) with CRH or DDAVP stimulation was performed and considered consistent with $C D$ with an inferior petrosal sinus to peripheral ACTH ratio (IPS/P) greater than 3.0 [33]. In addition, familial history of pituitary adenomas or endocrine tumors was carefully assessed and systematic measurement of levels of calcium was performed to exclude coexistent hyperparathyroidism.

All patients underwent transsphenoidal adenomectomy and surgical remission was defined as early postoperative concentrations of morning plasma cortisol below $3 \mu \mathrm{g} / \mathrm{dl}(85 \mathrm{nmol} / \mathrm{l})$. The tumor samples were collected during surgery. Part of the tissue was separated for routine histopathological examination and part was immediately frozen and microdissected to isolate tumoral tissue. The microdissected sample was mechanically disrupted and stored at $-70{ }^{\circ} \mathrm{C}$ for molecular studies. The control group for gene expression experiments included seven normal pituitary (NP) tissues obtained during autopsies as previously described [13]. Furthermore, hematoxylin-eosin staining was performed to confirm the presence of the tumor or to exclude incidental pituitary adenoma in NP.

\section{Nucleic acid extraction}

DNA and RNA were isolated by TRIzol ${ }^{\circledR}$ reagent (Invitrogen/Thermo Fisher Scientific, Carlsbad, CA, USA). Sample integrity was evaluated by spectrophotometry at an absorbance of 260/280 nm using NanoDrop ${ }^{T M}$ 2000/2000c (Thermo Fisher Scientific, Wilmington, Delaware, USA) and by agarose gel electrophoresis.

\section{USP8 mutation screening}

The exon 14 of the USP8 gene was amplified by PCR using primers previously described [34]. The amplified products were sequenced using a commercial kit (Big Dye ${ }^{\mathrm{TM}}$ Terminator Cycle Sequencing; Applied Biosystems/Thermo Fisher Scientific, Foster City, CA, USA). The acquired sequences were compared to USP8 reference sequence (GenBank NM_005154.4) using the CodonCode Aligner Program V4.0.4 (CodonCode Co.).

\section{Reverse transcription PCR and real-time PCR quantification}

From 32 tumor samples submitted to USP8 sequencing by Sanger method, RNA was available in a subset of 21 tumor samples. In these samples, cDNA was obtained using High Capacity cDNA Re- 
verse Transcription kit (Applied Biosystems/Thermo Fisher Scientific, Foster City, CA, USA). To evaluate the expression of genes involved in the cell cycle control, qPCR was performed by 7500 RTPCR System (Applied Biosystems/ Thermo Fisher Scientific, Foster City, CA, USA) using TaqMan ${ }^{\circledR}$ Gene Expression Assays: CDKN1B (Hs01597588_m1), CCNE1 (Hs01026536_m1), CCND1 (Hs0027 7039_m1), CDK2 (Hs01548894_m1), CDK4 (Hs00175935_m1), CDK6 (Hs01026371_m1) and reference genes: PGK1 (4326318E), TBP (4326322E) and GUSB (4326320E). Relative expression was calculated using the $2^{-\Delta \Delta \mathrm{Ct}}$ method, as previously described $[13,35]$.

\section{Immunohistochemistry (IHC)}

IHC anti-P27 was performed in all tumor samples. The paraffin-embedded samples underwent deparaffinization, rehydrataion, antigen retrieval (citrate buffer $\mathrm{pH} 6.0$ for $40 \mathrm{~min}$ at $100{ }^{\circ} \mathrm{C}$ ), peroxide block, rinse, protein block, rinse, and incubation with 1:200 P27/CDKN1B primary antibody (SAB4300420) (Sigma-Aldrich, St Louis, MO, USA) overnight at room temperature. The signal was amplified with the horseradish peroxidase polymer method (MACH1 Universal HRP-Polymer Detection, Biocare Medical, Concord, CA, USA). The chromogen used was DAB and the counterstaining was performed with hematoxylin. Normal pituitary tissue was used as positive control.

Each sample was assigned into two categories according to the following score: category A documented the number of immunoreactive cells as $0(<10 \%), 1(\geq 10<50 \%)$, and $2(\geq 50 \%)$; category $B$ documented the intensity of the immunostaining as 1 (no or weak) and 2 (moderate or strong). The values for categories $A$ and $B$ were added to provide the immunoreactivity score, ranging from 1 to 4 (scores 1, 2 = low expression; score 3 = moderate expression; and score 4 = high expression). The stained tumor tissues were scored while blinded to the clinical or molecular data.

\section{Statistical analysis}

Data are presented as mean \pm standard deviation, median and interquartile range. Mann-Whitney tests were used for continuous variables and Fisher's exact tests for categorical variables. Differences were considered significant at $p<0.05$. Data were analyzed by GraphPad Prism 5 software.

\section{Results}

Individual clinical, laboratorial, and molecular data of the 32 studied patients can be seen in $>$ Table 1 . As expected for studies evaluating Cushing's disease in adults, females were more represented than males and the majority of the patients presented microadenomas [36]. Twenty-four out of the 32 patients exhibited microadenomas and the tumors did not present cavernous sinus invasion. All patients presented high levels of LNSC (85.4 \pm 80.9 nmol/l, range 23.1-497.4), no salivary cortisol suppression after LDDST $(70.0 \pm 50.3 \mathrm{nmol} / \mathrm{l}$, range 9.1-222.6), and high ACTH levels (18.5 $\pm 9.3 \mathrm{pmol} / \mathrm{l}$, range 7.8-42.0). After HDDST, we observed plasma cortisol suppression of $68.6 \pm 27.0 \%$. Regarding ACTH increment after CRH or DDAVP stimulation tests, we observed $103.6 \pm 89.8$ and $125.8 \pm 148.1 \%$ of increment, respectively. Fourteen out of 32 patients were submitted to BIPSS and in all of them the IPS/P gradient confirmed the pituitary etiology. The majority of patients (29/32) underwent transsphenoidal surgery as first choice therapy; two patients were preoperatively treated with ketoconazole, and one with bilateral adrenalectomy due to the severity of the disease. After transsphenoidal surgery, the remission rate was $65.6 \%$; patients with persistent disease were submitted to complementary therapy with a second transsphenoidal surgery, or ketoconazole, or adrenalectomy, or radiotherapy, or combination of them.

\section{USP8 mutations and clinical phenotype}

In 10 out of the 32 tumors (31.3\%) we observed mutations in the exon 14 of USP8. The mutation c.C2159G (p.P720R) was observed in 5 patients, the c.2151_2153delCTC (p.S718del) in 3 patients, while 2 other mutations were observed each in one patient: $c$. T2152C (p.S718P) and c.2155_2169delTCCCCAGATATAACC (p. S719_T723del). All these mutations have been previously described [20, 21,34].

Patients harboring somatic USP8 mutations exhibited similar age of presentation than patients without USP8 mutations. They also presented similar late night salivary cortisol, salivary cortisol after LDDST, ACTH levels, and postoperative plasma cortisol levels. We observed superior tumor size in patients harboring USP8 mutations $(p=0.04)$. Both groups had similar rates of remission ( Table 2).

\section{Gene expression}

We performed Real Time PCR in samples obtained from 21 patients (7 of them harboring USP8 mutations). We observed no differences regarding the gene expression of the cell cycle regulators $C D$ KN1B (P27), CCNE1 (CYCLIN-E1), CCND1 (CYCLIN-D1), CDK2, CDK4, and CDK6 according to USP8 mutation status ( $\triangleright$ Table 3 ).

\section{Immunohistochemistry}

P27 (CDKN1B) was expressed in 31 pituitary adenomas. In one case, there was no sufficient tissue for IHC analysis. - Fig. 1 shows representative examples of photomicrographs of the immunohistochemical analysis. In tumors harboring the USP8 mutation, low to moderate positivity was observed in 6 (66.7\%), and high positivity in $3(33.3 \%)$ of the analyzed adenomas. Similarly, in tumors without the USP8 mutation, low to moderate positivity was observed in $14(63.6 \%)$, and high positivity in $8(36.3 \%)$ of the analyzed adenomas $(p=1.0)$. Regarding the staining pattern, in the tumors harboring the USP8 mutation, we observed predominant nuclear in only one tumor (11.1\%), predominant cytoplasm in 3 (33.3\%), and only cytoplasm in 5 (55.6\%). In the tumors without the mutation, the staining pattern was predominant nuclear in $6(27.3 \%)$, predominant cytoplasm in 10 (45.4\%), and only cytoplasm in 6 $(27.3 \%)(p=0.6)$.

\section{Discussion}

In the present study, we detected USP8 somatic mutations in $31.3 \%$ of Brazilian patients with Cushing's disease. Patients harboring somatic USP8 mutations exhibited superior tumor size but similar clinical and biochemical phenotype, and similar pattern of expression of cell cycle regulators suggesting that USP8 mutations might not be implicated in cell cycle dysregulation in corticotroph adenomas. 
Table 1 Clinical and laboratorial features of Cushing's disease patients.

\begin{tabular}{|c|c|c|c|c|c|c|c|c|}
\hline $\begin{array}{l}\text { Pa- } \\
\text { tient }\end{array}$ & USP8 mutation status & $\begin{array}{l}\text { Age at } \\
\text { diagnosis } \\
\text { (years) }\end{array}$ & Sex & $\begin{array}{l}\text { LNSC } \\
\text { (nmol/I) }\end{array}$ & $\begin{array}{l}\text { Salivary } \\
\text { cortisol post } \\
\text { LDDST (nmol/I) }\end{array}$ & $\begin{array}{l}\text { ACTH } \\
\text { (pmol/l) }\end{array}$ & $\begin{array}{l}\text { Tumor Size } \\
(\mathrm{cm}) \text { (MRI) }\end{array}$ & IHC \\
\hline 1 & WT & 31 & M & 85.12 & NA & 33.9 & after Adx - 0.9 & ACTH + \\
\hline 2 & $\begin{array}{l}\text { Del c.2155_2169del TCCCCAGA- } \\
\text { TATAACC (p.S719_T723del) }\end{array}$ & 45 & $\mathrm{~F}$ & 63.42 & 64.68 & 16.3 & 1.0 & $\mathrm{ACTH}+, \mathrm{CAM} .2+$ \\
\hline 3 & Del c.2151_2153delCTC (p.S718del) & 26 & $\mathrm{~F}$ & 47.6 & 112.0 & 28.4 & 0.8 & $\mathrm{ACTH}+$ \\
\hline 4 & WT & 54 & $\mathrm{~F}$ & 46.06 & 70.0 & 11.7 & 0.3 & $\mathrm{ACTH}+, \mathrm{ki} 67<1 \%$ \\
\hline 5 & c.T2152C (p.S718P) & 38 & $\mathrm{~F}$ & 145.32 & 81.48 & 18.4 & no tumor & negative \\
\hline 6 & WT & 26 & $\mathrm{~F}$ & 94.08 & 73.92 & 13.0 & no tumor & $\mathrm{ACTH}+$ \\
\hline 7 & WT & 39 & $\mathrm{~F}$ & 57.82 & 112.0 & 18.5 & 0.3 & inconclusive \\
\hline 8 & WT & 11 & $\mathrm{~F}$ & 131.6 & 103.32 & 16.6 & 0.4 & $\mathrm{ACTH}+$ \\
\hline 9 & WT & 36 & $\mathrm{~F}$ & 57.68 & 94.5 & 10.8 & 2.0 & $\mathrm{ACTH}+$ \\
\hline 10 & WT & 64 & $\mathrm{~F}$ & 48.44 & 30.8 & 30.6 & 0.5 & ACTH+, focal Gal-3 \\
\hline 11 & WT & 19 & $\mathrm{~F}$ & 94.08 & 81.48 & 11.3 & 0.5 & inconclusive \\
\hline 12 & WT & 23 & $\mathrm{~F}$ & 89.6 & 9.1 & 11.3 & 0.4 & $\mathrm{ACTH}+$ \\
\hline 13 & Del c.2151_2153delCTC(p.S718del) & 32 & $\mathrm{~F}$ & 86.8 & 100.8 & 25.8 & 0.6 & $\mathrm{ACTH}+$ \\
\hline 14 & c.C2159G (p.P720R) & 17 & $\mathrm{~F}$ & 109.2 & 44.8 & 11.1 & 3.6 & ACTH + \\
\hline 15 & WT & 34 & $\mathrm{~F}$ & 69.72 & 222.6 & 42.0 & 0.4 & ACTH+ \\
\hline 16 & WT & 35 & $\mathrm{~F}$ & 68.6 & 47.32 & 41.6 & 0.6 & $\begin{array}{l}\text { ACTH+, invasion in } \\
\text { neurohypophysis }\end{array}$ \\
\hline 17 & WT & 33 & $\mathrm{~F}$ & 39.2 & 21.28 & 15.8 & 0.3 & $\mathrm{ACTH}+$ \\
\hline 18 & WT & 31 & $\mathrm{~F}$ & 68.46 & 26.32 & 23.3 & 0.9 & $\mathrm{ACTH}+$ \\
\hline 19 & c.C2159G (p.P720R) & 21 & $\mathrm{~F}$ & 102.2 & 45.92 & 7.8 & 1.2 & $\mathrm{ACTH}+$ \\
\hline 20 & c.C2159G (p.P720R) & 24 & $\mathrm{~F}$ & 23.1 & 32.62 & 7.8 & 1.9 & $\mathrm{ACTH}+, \mathrm{MIB} 18 \%$ \\
\hline 21 & Del c.2151_2153delCTC (p.S718del) & 27 & $\mathrm{~F}$ & 54.88 & 20.16 & 21.0 & 0.5 & $\mathrm{ACTH}+$ \\
\hline 22 & WT & 35 & $\mathrm{~F}$ & 37.38 & 43.68 & 15.5 & 0.3 & $\mathrm{ACTH}+$ \\
\hline 23 & WT & 47 & $\mathrm{~F}$ & 35.56 & 61.74 & 19.9 & 0.2 & ACTH + \\
\hline 24 & WT & 29 & $\mathrm{~F}$ & 106.4 & 112.0 & 20.2 & 0.5 & hyperplasia \\
\hline 25 & WT & 14 & $\mathrm{~F}$ & 112.0 & 112.0 & 10.2 & 0.6 & $\mathrm{ACTH}+$ \\
\hline 26 & WT & 43 & $\mathrm{~F}$ & 36.68 & 35.84 & 11.3 & 0.5 & ACTH + \\
\hline 27 & c.C2159G (p.P720R) & 23 & $\mathrm{~F}$ & 43.54 & 31.78 & 7.9 & 0.5 & negative \\
\hline 28 & WT & 31 & $\mathrm{~F}$ & 52.22 & 70.98 & 26.0 & 2.0 & $\begin{array}{l}\text { ACTH+, ki67 3\% } \\
\text { (Crooke) }\end{array}$ \\
\hline 29 & WT & 47 & $\mathrm{~F}$ & 497.42 & 209.44 & 28.2 & 1.2 & ACTH +/Crooke \\
\hline 30 & WT & 27 & $\mathrm{~F}$ & 89.6 & 36.68 & 10.8 & 0.6 & ACTH and $\mathrm{GH}+$ \\
\hline 31 & WT & 49 & $\mathrm{~F}$ & 48.3 & 14.84 & 14.0 & 0.5 & inconclusive \\
\hline 32 & c.C2159G (p.P720R) & 44 & $\mathrm{~F}$ & 91.0 & 47.6 & 12.9 & 1.0 & $\mathrm{ACTH}+$ \\
\hline
\end{tabular}

LNSC: Late-night salivar cortisol; LDDST: Low-dose (1 mg overnight), dexamethasone supression test; MRI: Magnetic ressonance imaging; IHC: Immunohistochemistry; WT: Wild type, F: Female; M: Male, NA: Not available, Adx: Adrenalectomy. a: Patient submitted to Liddle 1 test. Patients 4 , $5,6,12,15,16,17,21,22,23,24,25,26$, and 31 were submitted to bilateral inferior petrosal sinus sampling.

The observed frequency of USP8 mutations in this study (31.3\%) is in agreement with previous worldwide series, reporting USP8 mutations in 35-60\% of corticotroph adenomas [20, 21, 34, 37, 38]. The age of presentation, LNSC, salivary cortisol after LDDST, ACTH levels, and rates of remission of our patients harboring USP8 mutations were similar to the patients without mutations, reinforcing the scant data available on this issue [21, 34, 37]. In our series, com- prised majority by women, a larger tumor size in patients harboring USP8 mutations was observed. In accordance with our data, a European study observed that tumors with USP8 mutations were slightly larger than wild-type tumors in female patients [34], whereas studies evaluating Asiatic populations observed inferior tumor size in the presence of USP8 mutations [21,37]. These differences could be potentially ascribed to different genetic back- 
grounds related to ethnicity. Of note, our patients are from the Brazilian Southeast, whose population background has been shaped by immigrants from several countries of Europe, including Italy, Spain, and Germany [39]. In addition, it is not possible to rule out an effect of estrogens on USP8 mutant corticotroph cells $[34,40]$.

P27 underexpression has been extensively demonstrated in different series of pituitary adenomas [5-8]. Recently, our lab also demonstrated P27 nuclear underexpression, even in tumors exhibiting CDKN1B mRNA normally expressed, suggesting that post-transcriptional mechanisms could underlie P27 underexpression in pituitary adenomas. However, we showed that P27 aberrant expres-

- Table 2 Clinical features of Cushing's disease patients according to USP8 mutation status.

\begin{tabular}{|c|c|c|c|}
\hline & $\begin{array}{l}\text { USP8 mutated } \\
\text { tumors }(n=10)\end{array}$ & $\begin{array}{l}\text { USP8 wild-type } \\
(\mathrm{n}=22)\end{array}$ & p \\
\hline $\begin{array}{l}\text { Age of presenta- } \\
\text { tion (years) }\end{array}$ & $\begin{array}{l}29.7 \pm 9.7 \\
26.5[22.5-39.5]\end{array}$ & $\begin{array}{l}34.4 \pm 12.7 \\
33.5[26.75-44.0]\end{array}$ & 0.3 \\
\hline $\begin{array}{l}\text { Late-night salivary } \\
\text { cortisol (nmol/l) }\end{array}$ & $\begin{array}{l}76.7 \pm 36.8 \\
75.1[46.6-104.0]\end{array}$ & $\begin{array}{l}89.3 \pm 95.1 \\
68.5[47.7-94.1]\end{array}$ & 0.84 \\
\hline $\begin{array}{l}\text { Salivary cortisol } \\
\text { post LDDST } \\
\text { (nmol/l) }\end{array}$ & $\begin{array}{l}58.2 \pm 30.846 .8 \\
{[32.4-86.3]}\end{array}$ & $\begin{array}{l}75.7 \pm 57.1 \\
70.0[33.3-107.7]\end{array}$ & 0.62 \\
\hline ACTH (pmol/l) & $\begin{array}{l}15.7 \pm 7.5 \\
14.6[7.9-22.2]\end{array}$ & $\begin{array}{l}19.8 \pm 9.9 \\
16.2[11.3-26.5]\end{array}$ & 0.26 \\
\hline $\begin{array}{l}\text { Maximum tumor } \\
\text { diameter }(\mathrm{mm})\end{array}$ & $\begin{array}{l}11.1 \pm 10.1 \\
9[5-13.7]\end{array}$ & $\begin{array}{l}5.7 \pm 5.4 \\
5[3-6]\end{array}$ & 0.04 \\
\hline $\begin{array}{l}\text { Postoperative } \\
\text { plasma cortisol } \\
(\mathrm{nmol} / \mathrm{l})\end{array}$ & $\begin{array}{l}166.3 \pm 177.3 \\
45.5[33.0-346.2]\end{array}$ & $\begin{array}{l}84.6 \pm 112.3 \\
33.0[33.0-106.3]\end{array}$ & 0.20 \\
\hline Remission & $40 \%(4 / 10)$ & $63.6 \%(14 / 22)$ & 0.27 \\
\hline
\end{tabular}

Data expressed as mean \pm standard deviation, median [interquartile range], except for remission. LDDST: Low-dose dexamethasone suppression test. sion in pituitary tumors could not be explained by dysregulation of several CDKN1B translational controllers (DKC1, RPS13, miR221, miR222) or by DKC1 mutations [13]. In the present study, we speculated that USP8 exon 14 mutations could promote P27 insufficiency and consequential cell cycle dysfunction via EGR pathway activation in corticotroph adenomas.

Our findings on gene expression of CDKN1B (P27), CCNE1, CCND1, CDK2, CDK4, and CDK6 showed no significant differences between WT and USP8 mutant groups. In addition, based on our mechanistic hypothesis, we evaluated cell cycle regulators not only at transcript level, but also the P27/CDKN1B protein. We found no significant difference in $\mathrm{P} 27$ protein expression between WT and USP8 mutant groups, neither in immunoreactivity score nor in cell compartment distribution, suggesting no relationship between cell cycle regulators and USP8 mutations in corticotroph adenomas.

It has been previously shown that corticotroph adenomas harboring USP8 mutations display higher EGFR expression [21] and AtT20 cells treated with USP8 inhibitor exhibited downregulation of EGFR expression [41]. However, Hayashi et al. observed no significant differences in EGFR mRNA or IHC expression between USP8 WT and mutant adenomas [37]. In accordance, Ballmann et al. observed EGFR negative IHC staining in USP8 mutant adenomas [42]. In vitro functional analysis of USP8 mutations revealed increased deubiquitinase activity, which inhibits the downregulation of EGFR, but this finding was not replicated in vivo [37]. Some of these differences could be ascribed to the use of different antibodies against the EGFR [43].

One of the main strengths of this single center study was the homogeneity of the diagnostic and postoperative management protocols, allowing a comprehensive phenotypic characterization. The limitation was the relatively small number of samples carrying USP8 somatic mutations in our series. Nonetheless, this study originally demonstrated that the aberrant expression of P27 in corticotroph adenomas is unrelated to USP8 mutations. Hence, additional studies are required to elucidate the role of USP8 mutations in Cushing's disease to adequately determine suitable patients for directed therapies.

- Table 3 Relative gene expression of cell cycle regulators in corticotroph adenomas according to USP8 mutation status.

\begin{tabular}{|l|l|l|}
\hline Gene & $\begin{array}{l}\text { USP8 mutated Tumors (Relative Expression 2- } \mathbf{\Delta \Delta C t} \text { ) } \\
\text { mean } \pm \text { SD median [Q2-Q4] }\end{array}$ & $\begin{array}{l}\text { USP8 non-mutated Tumors (Relative Expression 2- } \Delta \Delta C t) \\
\text { mean } \pm \text { SD median [Q2-Q4] }\end{array}$ \\
\hline CDKN1B (P27) & $0.85 \pm 0.91$ & $1.34 \pm 1.03$ \\
\hline $0.35[0.08-1.65]$ & $1.13[0.60-2.19]$ \\
\hline CDK2 & $2.31 \pm 1.70$ & $2.09 \pm 1.22$ \\
\hline & $1.53[0.88-3.70]$ & $1.91[1.02-3.20]$ \\
\hline CDK4 & $0.60 \pm 0.25$ & $0.90 \pm 0.80$ \\
\hline & $0.72[0.35-0.78]$ & $0.63[0.39-0.94]$ \\
\hline CDK6 & $0.44 \pm 0.52$ & $0.72 \pm 0.62$ \\
\hline & $0.08[0.02-1.02]$ & $0.48[0.16-1.32]$ \\
\hline CCNE1 & $2.10 \pm 2.26$ & $1.74 \pm 1.53$ \\
\hline$(C Y C L I N E 1)$ & $1.40[0.70-1.98]$ & $1.05[0.74-2.47]$ \\
\hline CCND1 & $0.60 \pm 0.37$ & $0.93 \pm 0.66$ \\
\hline (CYCLIN D1) & $0.55[0.26-0.90]$ & $0.70[0.48-1.25]$ \\
\hline
\end{tabular}




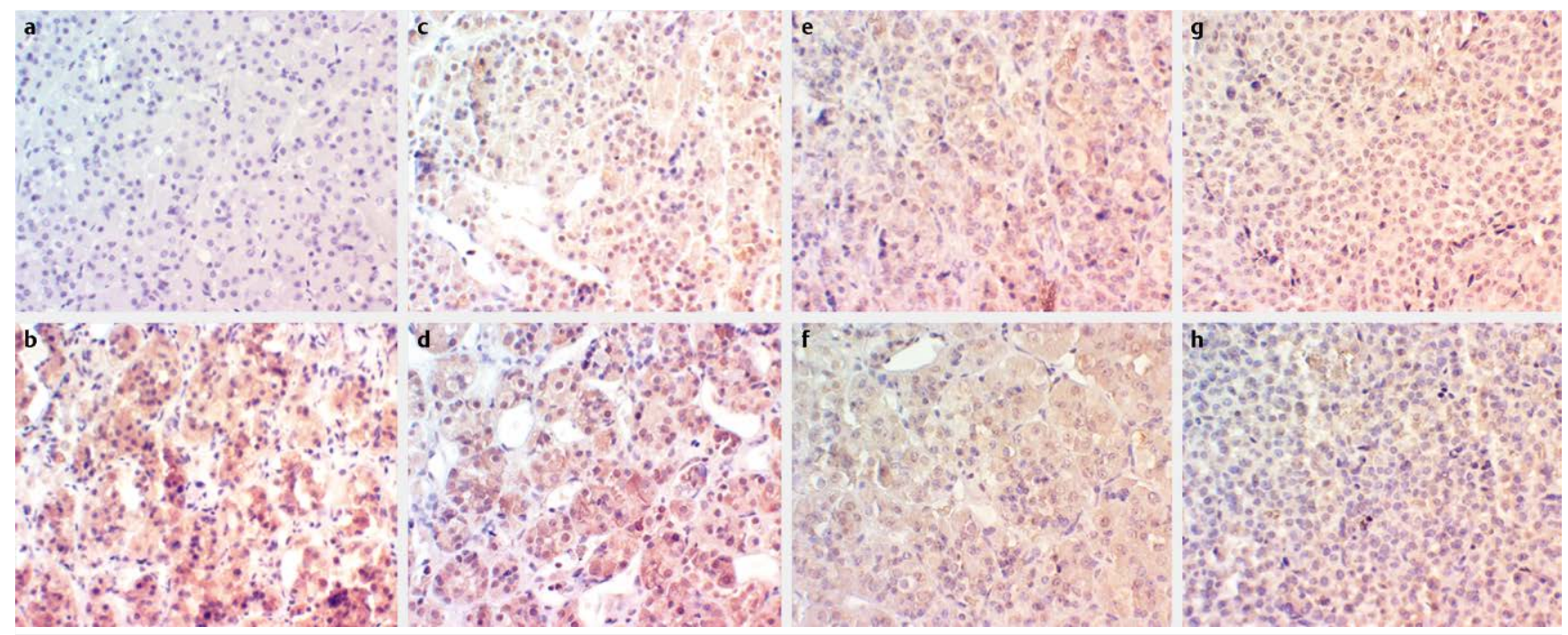

- Fig. 1 Representative photomicrographs of immunohistochemical analysis: Negative control of P27/CDKN1B immunohistochemistry, with no primary antibody added, in a specimen of normal pituitary $(\times 400)$ a. Positive control of P27/CDKN1B immunohistochemistry in a specimen of normal pituitary $(\times 400)$ b. Histologic specimens of USP8 mutated ACTH-secreting pituitary adenomas $(\times 400)$ with P27/CDKN1B immunohistochemistry showing moderate positive score and predominant nuclear staining $\mathbf{c}$; moderate positive score and predominant cytoplasm staining e; and low positive score and predominant cytoplasm staining $\mathbf{g}$. Histologic specimens of USP8 wild type ACTH-secreting pituitary adenomas $(\times 400)$ with P27/ CDKN1B immunohistochemistry showing strong positive score and predominant nuclear staining $\mathbf{d}$; moderate positive score and predominant cytoplasm staining $\mathbf{f}$; and low positive score and predominant cytoplasm staining $\mathbf{h}$.

In conclusion, in this Brazilian series of patients with Cushing's disease, the observed frequency of USP8 somatic mutations was similar to that reported in European ancestry populations. Although it was reasonable that USP8 mutations could contribute to cell cycle dysregulation and P27 underexpression in corticotroph adenomas, our data did not confirm this hypothesis. It is possible that increased deubiquitinase activity observed in mutated USP8 corticotroph adenomas might influence $\mathrm{P} 27$ post-translational phosphorylation or other pathways involved in cell growth and proliferation. Furthermore, other phenomena, unrelated to USP8 mutations may also regulate P27 underexpression in corticotroph adenomas.

\section{Author Contributions}

C.S.M. and M.C. planned the study, analyzed data, and wrote the manuscript. C.S.M. and R.C.C. performed gene expression studies. C.S.M and F.B.C.L performed genetic analysis. F.P.S. performed the macrodissection of histopathological specimens and the IHC analysis. C.S.M. collected clinical data and performed statistical analysis. A.C.M contributed with critical analysis of the data. All authors reviewed the manuscript.

\section{Funding Information}

The authors thank the National Counsel of Technological and Scientific Development (CNPq) (Grant No 150569/2015-7) and the São Paulo Research Foundation (FAPESP) (Grant No 2014/03989-6) for financial support.

\section{Acknowledgements}

The authors thank Deise Lucia Chesca, Rubens Melo, Rogério Lenotti Zuliani, Wendy Turatti, and Aline Turatti for technical support. The authors thank Prof. Helio Rubens Machado for performing the transsphenoidal surgeries. The authors thank Prof. Luciano Neder (Laboratory of Neuropathology, Pathology Department) and Prof. Ana Maria Ferreira Roselino (Dermatology Laboratory, Internal Medicine Department) from the Ribeirao Preto Medical School, University of Sao Paulo for their support of this work.

\section{Conflict of Interest}

The authors declare that they have no conflict of interest.

References

[1] Quereda V, Malumbres M. Cell cycle control of pituitary development and disease. J Mol Endocrinol 2009; 42: 75-86

[2] Nakayama K, Ishida N, Shirane M et al. Mice lacking p27(Kip1) display increased body size, multiple organ hyperplasia, retinal dysplasia, and pituitary tumors. Cell 1996; 85: 707-720

[3] Pellegata NS, Quintanilla-Martinez L, Siggelkow H et al. Germ-line mutations in p27Kip1 cause a multiple endocrine neoplasia syndrome in rats and humans. Proc Natl Acad Sci USA 2006; 103: 15558-15563

[4] Simpson D], Frost SJ, Bicknell JE et al. Aberrant expression of $G(1) / S$ regulators is a frequent event in sporadic pituitary adenomas. Carcinogenesis 2001; 22: 1149-1154

[5] Jin L, Qian X, Kulig E et al. Transforming growth factor-beta, transforming growth factor-beta receptor II, and p27Kip1 expression in nontumorous and neoplastic human pituitaries. Am J Pathol 1997; 151: 509-519 
[6] Lidhar K, Korbonits M, Jordan S et al. Low expression of the cell cycle inhibitor p27Kip1 in normal corticotroph cells, corticotroph tumors, and malignant pituitary tumors. J Clin Endocrinol Metab 1999; 84: 3823-3830

[7] Bamberger CM, Fehn M, Bamberger AM et al. Reduced expression levels of the cell-cycle inhibitor p27Kip1 in human pituitary adenomas. Eur J Endocrinol 1999; 140: 250-255

[8] Lloyd RV, Jin L, Qian X et al. Aberrant p27kip1 expression in endocrine and other tumors. Am J Pathol 1997; 150: 401-407

[9] Dahia PL, Aguiar RC, Honegger J et al. Mutation and expression analysis of the p27/kip1 gene in corticotrophin-secreting tumours. Oncogene 1998; 16: 69-76

[10] Tanaka C, Yoshimoto K, Yang P et al. Infrequent mutations of p27Kip1 gene and trisomy 12 in a subset of human pituitary adenomas. J Clin Endocrinol Metab 1997; 82: 3141-3147

[11] Takeuchi S, Koeffler HP, Hinton DR et al. Mutation and expression analysis of the cyclin-dependent kinase inhibitor gene p27/Kip1 in pituitary tumors. J Endocrinol 1998; 157: 337-341

[12] Yoshino A, Katayama Y, Ogino A et al. Promoter hypermethylation profile of cell cycle regulator genes in pituitary adenomas. J Neurooncol 2007; 83: 153-162

[13] Martins CS, Camargo RC, Saggioro FP et al. P27/CDKN1B translational regulators in pituitary tumorigenesis. Horm Metab Res 2016; 48: $840-846$

[14] Musat M, Korbonits M, Pyle M et al. The expression of the F-box protein Skp2 is negatively associated with p27 expression in human pituitary tumors. Pituitary 2002; 5: 235-242

[15] Liu W, Asa SL, Ezzat S. Vitamin D and its analog EB1089 induce p27 accumulation and diminish association of p27 with Skp2 independent of PTEN in pituitary corticotroph cells. Brain Pathol 2002; 12: 412-419

[16] Korbonits M, Chahal HS, Kaltsas G et al. Expression of phosphorylated p27(Kip1) protein and Jun activation domain-binding protein 1 in human pituitary tumors. J Clin Endocrinol Metab 2002; 87: 2635-2643

[17] Musat M, Korbonits M, Kola B et al. Enhanced protein kinase B/Akt signalling in pituitary tumours. Endocr Relat Cancer 2005; 12 : 423-433

[18] Roussel-Gervais A, Couture C, Langlais D et al. The Cables1 gene in glucocorticoid regulation of pituitary corticotrope growth and cushing disease. J Clin Endocrinol Metab 2016; 101: 513-522

[19] Hernandez-Ramirez LC, Gam R, Valdes N et al. Loss-of-function mutations in the CABLES1 gene are a novel cause of Cushing's disease. Endocr Relat Cancer 2017; 24: 379-392

[20] Reincke M, Sbiera S, Hayakawa A et al. Mutations in the deubiquitinase gene USP8 cause Cushing's disease. Nat Genet 2015; 47: 31-38

[21] Ma ZY, Song Z], Chen JH et al. Recurrent gain-of-function USP8 mutations in Cushing's disease. Cell Res 2015; 25: 306-317

[22] Chen J, Jian X, Deng $S$ et al. Identification of recurrent USP48 and BRAF mutations in Cushing's disease. Nat Commun 2018; 9: 3171

[23] Mizuno E, lura T, Mukai A et al. Regulation of epidermal growth factor receptor down-regulation by UBPY-mediated deubiquitination at endosomes. Mol Biol Cell 2005; 16: 5163-5174

[24] Theodoropoulou M, Arzberger T, Gruebler Y et al. Expression of epidermal growth factor receptor in neoplastic pituitary cells: Evidence for a role in corticotropinoma cells. J Endocrinol 2004; 183: 385-394

[25] Fukuoka H, Cooper O, Ben-Shlomo A et al. EGFR as a therapeutic target for human, canine, and mouse ACTH-secreting pituitary adenomas. J Clin Invest 2011; 121: 4712-4721
[26] Schlessinger J, Ullrich A. Growth factor signaling by receptor tyrosine kinases. Neuron 1992; 9: 383-391

[27] Wang J, Barnes RO, West NR et al. Jab1 is a target of EGFR signaling in ERalpha-negative breast cancer. Breast Cancer Res 2008; 10: R51

[28] Pedroza-Saavedra A, Lam EW, Esquivel-Guadarrama F et al. The human papillomavirus type $16 \mathrm{E} 5$ oncoprotein synergizes with EGF-receptor signaling to enhance cell cycle progression and the down-regulation of p27(Kip1). Virology 2010; 400: 44-52

[29] Nieman LK, Biller BM, Findling JW et al. The diagnosis of Cushing's syndrome: an Endocrine Society Clinical Practice Guideline. J Clin Endocrinol Metab 2008; 93: 1526-1540

[30] Castro M, Elias PC, Quidute AR et al. Out-patient screening for Cushing's syndrome: the sensitivity of the combination of circadian rhythm and overnight dexamethasone suppression salivary cortisol tests. J Clin Endocrinol Metab 1999; 84: 878-882

[31] Elias PC, Martinez EZ, Barone BF et al. Late-night salivary cortisol has a better performance than urinary free cortisol in the diagnosis of Cushing's syndrome. J Clin Endocrinol Metab 2014; 99: 2045-2051

[32] Bertagna X, Guignat L, Groussin L et al. Cushing's disease. Best Pract Res Clin Endocrinol Metab 2009; 23: 607-623

[33] Arnaldi G, Angeli A, Atkinson AB et al. Diagnosis and complications of Cushing's syndrome: a consensus statement. ] Clin Endocrinol Metab 2003; 88: 5593-5602

[34] Perez-Rivas LG, Theodoropoulou M, Ferrau F et al. The gene of the ubiquitin-specific protease 8 is frequently mutated in adenomas causing cushing's disease. J Clin Endocrinol Metab 2015; 100: E997-E1004

[35] Livak KJ, Schmittgen TD. Analysis of relative gene expression data using real-time quantitative PCR and the 2(-Delta Delta C(T)) Method. Methods 2001; 25: 402-408

[36] Storr HL, Alexandraki KI, Martin L et al. Comparisons in the epidemiology, diagnostic features and cure rate by transsphenoidal surgery between paediatric and adult-onset Cushing's disease. Eur J Endocrinol 2011; 164: 667-674

[37] Hayashi K, Inoshita N, Kawaguchi K et al. The USP8 mutational status may predict drug susceptibility in corticotroph adenomas of Cushing's disease. Eur J Endocrinol 2016; 174: 213-226

[38] Faucz FR, Tirosh A, Tatsi C et al. Somatic USP8 gene mutations are a common cause of pediatric cushing disease. J Clin Endocrinol Metab 2017; 102: 2836-2843

[39] Souza MC, Martins CS, Silva-Junior IM et al. NR3C1 polymorphisms in Brazilians of Caucasian, African, and Asian ancestry: Glucocorticoid sensitivity and genotype association. Arq Bras Endocrinol Metabol 2014; 58: 53-61

[40] Zilio M, Barbot M, Ceccato F et al. Diagnosis and complications of Cushing's disease: Gender-related differences. Clin Endocrinol (Oxf) 2014; 80: 403-410

[41] Jian FF, Li YF, Chen YF et al. Inhibition of ubiquitin-specific peptidase 8 suppresses adrenocorticotropic hormone production and tumorous corticotroph cell growth in AtT20 Cells. Chin Med J (Engl) 2016; 129: 2102-2108

[42] Ballmann C, Thiel A, Korah HE et al. USP8 mutations in pituitary cushing adenomas-targeted analysis by next-generation sequencing. J Endocr Soc 2018; 2: 266-278

[43] Theodoropoulou M, Reincke M, Fassnacht M et al. Decoding the genetic basis of Cushing's disease: USP8 in the spotlight. Eur J Endocrinol 2015; 173: M73-M83 